Portland State University

PDXScholar

Fall 1-18-2013

\title{
Spectrum Regrowth for OFDM-based LTE and WIMAX Systems
}

Bosi Chen

Portland State University

Follow this and additional works at: https://pdxscholar.library.pdx.edu/open_access_etds

Part of the Systems and Communications Commons Let us know how access to this document benefits you.

Recommended Citation

Chen, Bosi, "Spectrum Regrowth for OFDM-based LTE and WIMAX Systems" (2013). Dissertations and Theses. Paper 601.

https://doi.org/10.15760/etd.601

This Thesis is brought to you for free and open access. It has been accepted for inclusion in Dissertations and Theses by an authorized administrator of PDXScholar. Please contact us if we can make this document more accessible: pdxscholar@pdx.edu. 


\section{SPECTRUM REGROWTH FOR OFDM-BASED LTE AND WIMAX SYSTEMS}

by
BOSI CHEN

A thesis submitted in partial fulfillment of the requirements for the degree of

MASTER OF SCIENCE

in

ELECTRICAL ENGINEERING

Thesis Committee:

$\mathrm{Fu}$ Li, Chair

James Morris

Xiaoyu Song

Portland State University

2012 


\begin{abstract}
In OFDM-based (Orthogonal Frequency Dimension Multiplexing) LTE (Long Term Evolution) and WiMAX (Worldwide Interoperability for Microwave Access) Systems, one of the critical components is the RF power amplifier. With current technologies, RF power amplifiers are not perfectly linear. The nonlinearity of an RF power amplifier is one of the main concerns in RF power amplifier design. The nonlinearity control is described by the out-of-band power emission levels, and the nonlinearity of an RF power amplifier is usually described by $I P_{3}$ (the third-order intercept point). However, there is need of a clear relationship or expression between the out-of-band power emission level and $I P_{3}$ for LTE and WiMAX Systems, which helps the RF designers to choose components.

This thesis presents the analysis of the nonlinear effect of an RF amplifier in LTE and WiMAX Systems, and the derivation of the expressions for the estimated out-of-band emission levels for LTE and WiMAX signals in terms of $I P_{3}$ and the power level of the signal.
\end{abstract}

The result will be helpful for RF engineers in the design and test of RF power amplifiers in LTE and WiMAX Systems. 


\section{Acknowledgements}

I am heartily thankful to my advisor and thesis committee chair, Dr. Fu Li, whose encouragement, guidance and support from the initial to the final stage enabled me to develop an understanding of this research. He introduced me to the various aspects of wireless communication systems. I am deeply grateful to the guidance that has been provided by Chunming Liu during my first steps into wireless communication research. Their probing comments and insightful suggestions are invaluable resources which made this research all possible.

I would like to thank Professors Xiaoyu Song and James Morris for their guidance and support as the members of my thesis committee. I also would like to express my appreciation to the staff of the Department of Electrical and Computer Engineering at Portland State University for their help and contribution in my graduate education. My appreciation should also be given to my peer Xiao $\mathrm{Li}$, the Ph.D student in our group, who gave me support and guidance during the time I did my research.

This thesis is dedicated to my family and friends for their constant and unconditional support and love. My special thanks go to my aunt Lila Lv for guiding me to study in US and providing me aborative care.

Lastly, I offer my appreciations to all of those who supported me in any respect during the completion of the project. 


\section{Table of Contents}

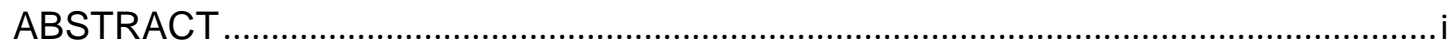

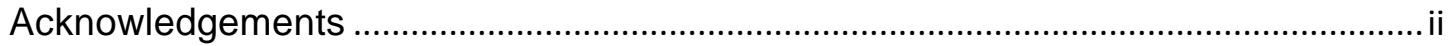

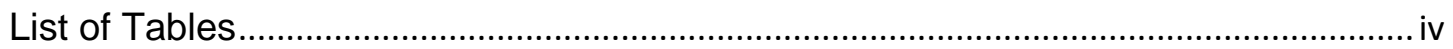

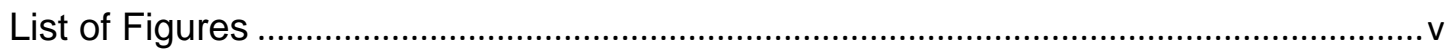

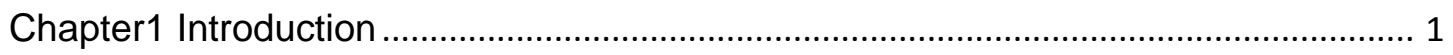

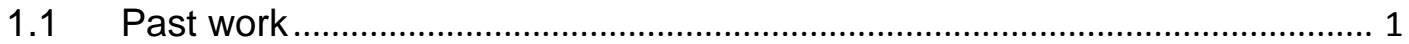

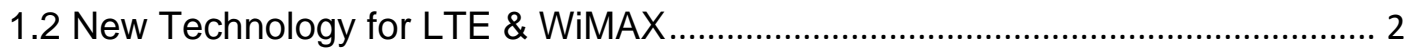

1.3 Research Approaches and Objectives................................................................. 3

Chapter 2 Nonlinearity of RF Power Amplifier ................................................................. 5

2.1 Introduction for RF Power Amplifier ...................................................................... 5

2.2 Intermodulation for RF Power Amplifier ................................................................. 7

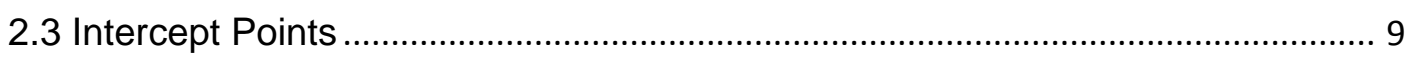

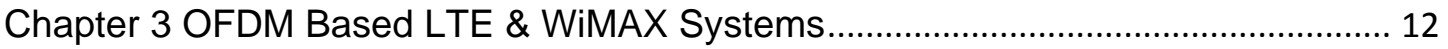

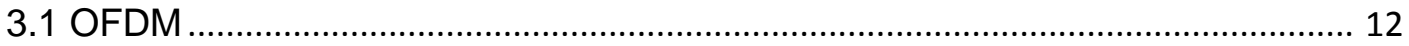

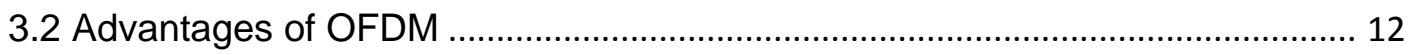

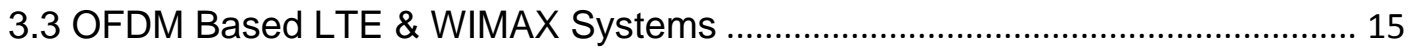

Chapter 4 Spectrum Regrowth for OFDM-based LTE \& WiMAX Systems .................. 20

4.1 The Equivalent Mathematical Model of LTE \& WiMAX Signals .......................... 20

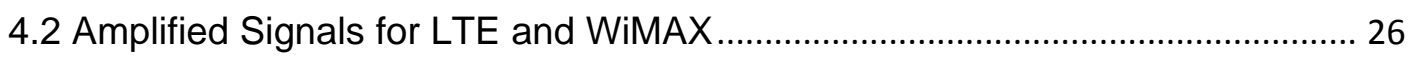

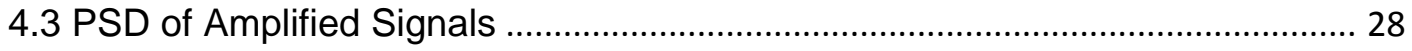

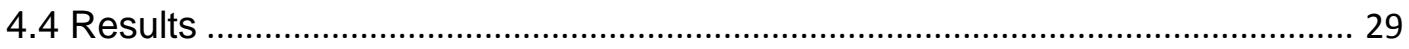

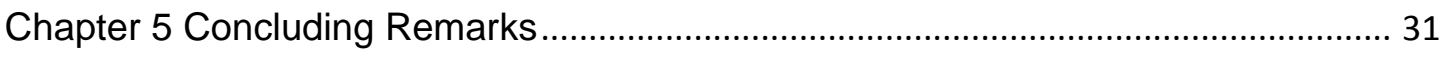

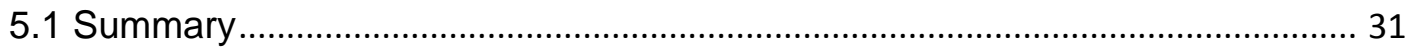

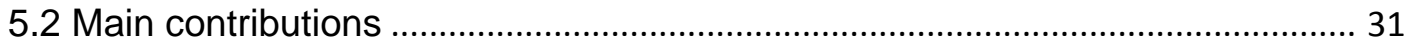

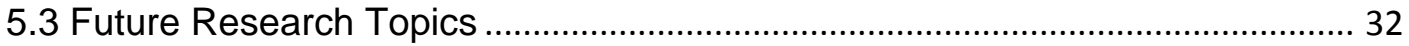

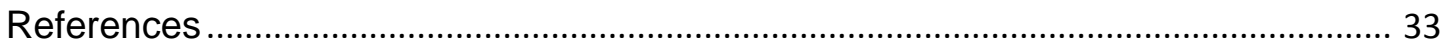




\section{List of Tables}

Table 3.1

Parameters used in math model for $10 \mathrm{MHz}$ rate

19 


\section{List of Figures}

Figure 2.1 Linear vs. Nonlinear Response 6

Figure 2.2 Spectrum of Products in a Two-tone System 7

Figure 2.3 Two-tone test for the third-order intermodulation levels. $\quad 10$

Figure 2.4 Two-tone test for the fifth-order intermodulation levels 11

$\begin{array}{lll}\text { Figure } 3.1 & \text { (a) Conventional multi-carrier technique } & 13\end{array}$

Figure 3.1 (b) Orthogonal multi-carrier modulation technique 13

$\begin{array}{lll}\text { Figure 3.2 Spectrum of a single modulated OFDM subcarrier } & 14\end{array}$

Figure 3.3 Spectrum of multiple OFDM subcarriers of constant 14 amplitude

Figure 3.4 OFDM symbol with multipath 15

Figure 3.5 OFDM symbol structure for normal cyclic prefix case 17

Figure 3.6 LTE 10MHz bandwidth simulation example 18

Figure 4.1 Sent and received signal with a guard interval time 20

Figure 4.2 16-QAM constellation bit encoding 22

Figure 4.3 Power spectrum comparison of downlink LTE and WiMAX 26 signal

Figure 4.4 Power spectrum comparison of amplified downlink LTE and 30 WiMAX signal. 


\section{Chapter1 Introduction}

\subsection{Past work}

Our research group in Portland State University has done extensive work in analyzing the nonlinearity of RF power amplifier of various wireless communication systems, such as CDMA (Code Division Multiple Access), TDMA (Time Division Multiple Access) by Heng Xiao, TD-SCDMA (Time Division Synchronous Code Division Multiple Access) by Xiao Li, and OFDM-based Wi-Fi (Wireless Fidelity) by Chunming Liu. My work is to advance this knowledge to LTE and WiMAX Systems.

Motivated by the increasing popularity of wireless communication, many researchers focused on this spectrum issue generated by the nonlinearity of power amplifiers. In the previous work at Portland State University led by Professor Fu Li in cooperation with Dr. Qiang $\mathrm{Wu}$ from the industry nearby, Dr. Heng Xiao has analyzed the spectrum regrowth of an RF power amplifier in CDMA (IS-95 standard), MIR, and GSM systems, and developed expressions for out-of-band emission levels of the signals in these systems in terms of the power amplifier's intermodulation coefficients as well as the power level and bandwidth of the signal [1,2]. Dr. Chunming Liu has developed expressions for TDMA (IS-54 standard), Motorola iDEN and Wi-Fi systems [3-5]. Xiao Li has analyzed the spectrum regrowth resulting from the nonlinear effects of an RF power amplifier in TD-SCDMA systems [6]. 


\subsection{New Technology for LTE \& WiMAX}

The past work has analyzed and predicted the spectrum regrowth caused by the nonlinearity of RF power amplifiers related to their intermodulation parameters for two OFDM based signals: Wi-Fi and digital broadcasting. In the work reported here, this technology is advanced further to LTE and WiMAX signals and verified by the validity of the theoretical result derived by real experiments. This provides insight for power amplifier design and digital predistortion in terms of out-band spectrum regrowth.

LTE and WiMAX are the two emerging technologies dominating for the fourth generation $(4 \mathrm{G})$ of mobile networks. The in-band and out-of-band emission limits are specified in these two systems, however, the mathematical descriptions on spectrum regrowth still lack in these relatively new standard.

Long term evolution (LTE) is a next generation mobile communication system, as a project of the 3rd Generation Partnership Project (3GPP), and WiMAX stands for Worldwide Interoperability for Microwave Access, and is another emerging wireless technology that provides high speed mobile data and telecommunication services based on IEEE 802.16 standards. Both LTE and WiMAX support frequency division duplexing (FDD) and time division duplexing (TDD) modes, and have more deployment flexibility than previous $3 \mathrm{G}$ systems by using scalable channel bandwidths with different numbers of subcarriers, keeping frequency spacing between subcarriers constant. Orthogonal frequency division multiplexing (OFDM) with cyclic prefix (CP) is used in the downlink of LTE systems and both the uplink 
and the downlink of WiMAX systems rather than signal carrier modulation schemes in traditional cellular systems. These two standards have set specific requirements in the terms of the power spectrum density (PSD) of the signal for the control of in-band and out-of-band spectrum regrowth. As a result, it is very important to know the relationship between the spectrum regrowth and nonlinear parameters of the system power amplifier.

\subsection{Research Approaches and Objectives}

In this thesis, this research is under Xiao Li's help and applied to Chunming Liu's previous work "Spectral Modeling and Nonlinear Distortion Analysis of OFDM Based Wireless LAN Signals". To develop a comprehensive approach toward spectrum analysis and modeling in the LTE and WiMAX system, we will

(1) create a mathematical model of the LTE and WiMAX signals, and use the amplifier model to analyze the amplified signals;

(2) analyze the spectrum regrowth resulting from the nonlinear effects of an RF power amplifier in LTE and WiMAX systems;

(3) find out the relationship between spectrum regrowth levels and the RF power amplifier's nonlinearity parameters;

(4) derive expressions relating the out-of-band power emission levels of an amplifier to its nonlinearities. 
This research attempts to match the theoretical result with computer-simulated and experimental measurement LTE and WiMAX signals spectrum regrowth. The evidence will be provided to verify the validity of the theoretical result.

The current research results would enable LTE and WiMAX wireless communication system designers to effectively specify and measure spectrum regrowth using simple RF power amplifier intermodulation descriptions and assist spectrum administrators to manage and plan spectrum allocation efficiently. 


\section{Chapter 2 Nonlinearity of RF Power Amplifier}

\subsection{Introduction for RF Power Amplifier}

In wireless communication, the RF power amplifier function is to boost the input modulated up-converted signal in order to enable the signal to propagate through the air. It is one of the critical and costly components in digital cellular communication systems.

In an ideal linear amplifier system, the output of the power amplifier is directly proportional to the input of the power amplifier, following the form of $y=m x+c$ (see figure $2.1[2])$. In reality, nonlinearities are always present in power amplifiers. They are not readily apparent because the resulting intermodulation products $\left(\mathrm{IMP}_{\mathrm{S}}\right)$ are significantly below the system noise floor as a result of relatively weak carrier signals. This situation becomes apparent when the incident power is raised above 30 $\mathrm{dBm}$ (power ratio in decibels of the measured power referenced to one milliwatt).

The small nonlinearities have characteristics similar to the characteristics of a square law (See Figure 2.1[2]). It is readily seen that the distortion to the waveform is due to the positive one-half-cycle being significantly greater in amplitude than the negative one-half-cycle. When converted to the frequency domain, this waveform consists of the desired fundamental plus a decaying series of related harmonics that, in themselves, interact with differ power emission levels present on the amplifier system.

The effect of this interaction produces additional frequencies, some occurring where they are least wanted (See Figure 2.2[2]). As shown in figure 2.2, all the third order 
$I M P$ (Intermodulation Product), i.e. $I M P_{3}$, (at $2 F_{1^{-}} F_{2}$ ); fifth-order $I M P$, i.e. $I M P_{5}$; (at $3 F_{1}-2 F_{2}$ ); seventh-order $I M P$, i.e. $I M P_{7}$, (at $4 F_{1}-3 F_{2}$ ); products can manifest themselves in the pass-band of signal and, if significantly large, they can degrade the quality of the signal, increase bit error rate, interfere with adjacent channels, and effectively block a channel by making the system perform as though a desired signal were present when it is actually not.

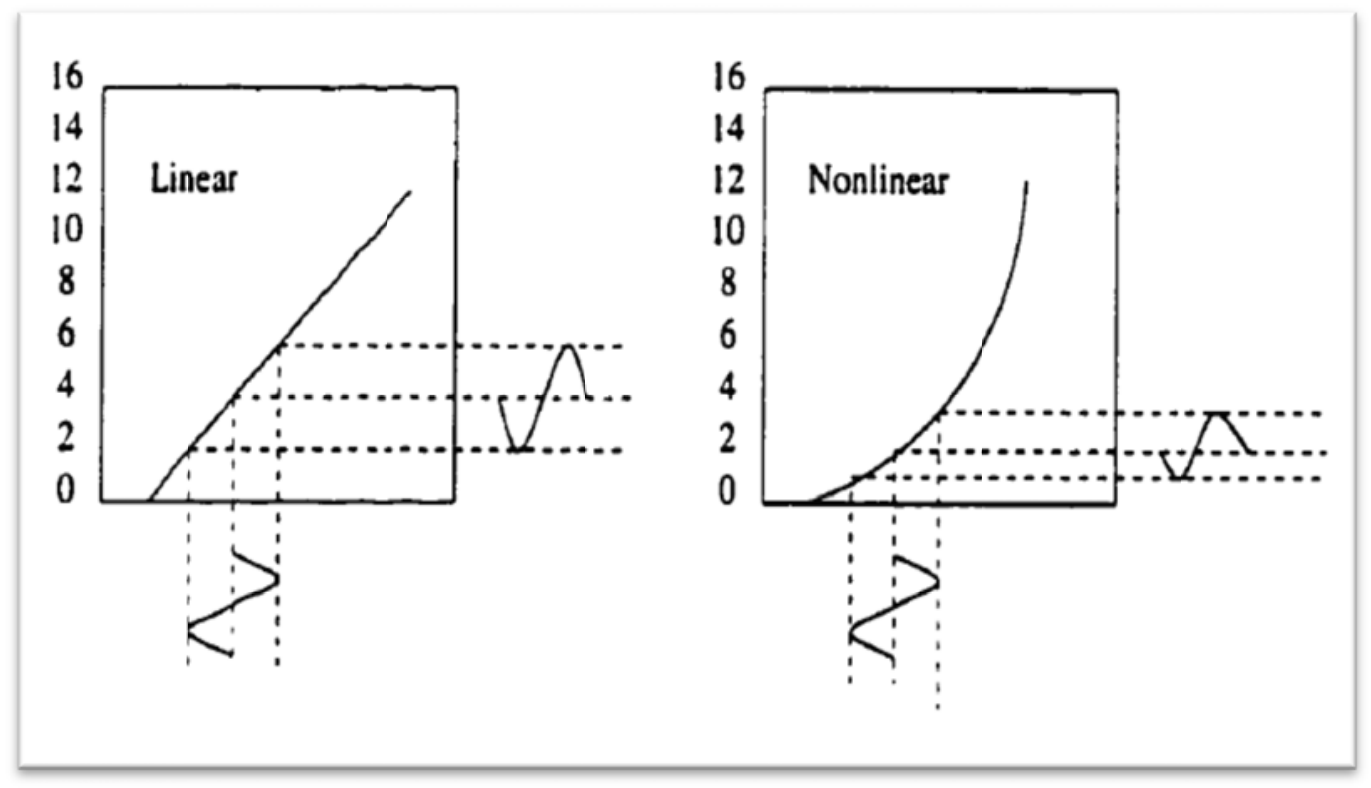

Fig 2.1: Linear vs. Nonlinear Response 


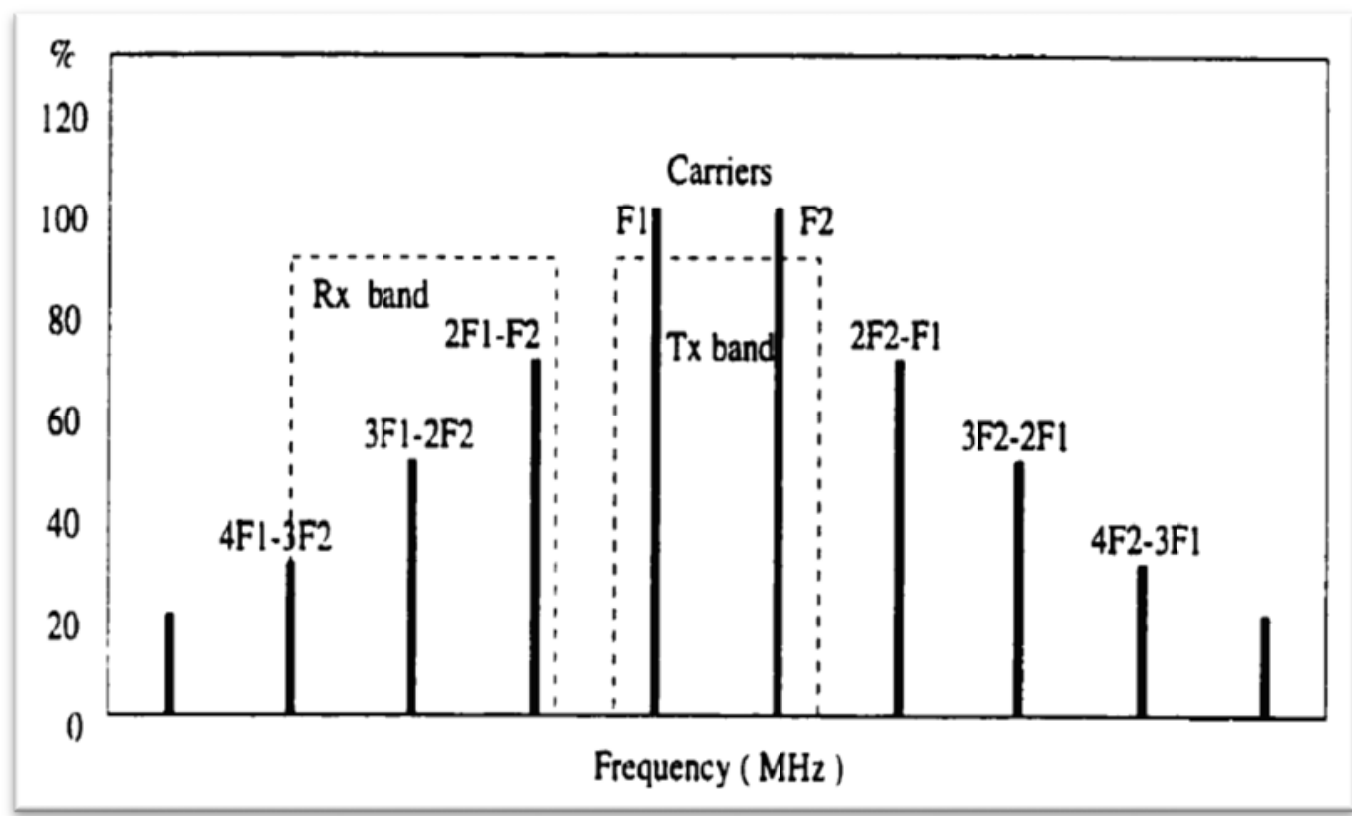

Fig 2.2: Spectrum of Products in a Two-tone System

\subsection{Intermodulation for RF Power Amplifier}

The primary concerns for cellular service providers are channel efficiency and clarity of transmission. Growth in demand for mobile communications has created a need to operate equipment at greater capacities and reliability to serve the competitive market.

These increased demands have exposed a condition within RF amplification referred to as intermodulation distortion. This condition occurs when nonlinearities within the power amplifiers generate other frequencies known as intermodulation products. Intermodulation deteriorates or limits the ability of the service providers to operate at optimal performance levels and ultimately may cause subscribers to experience poor call quality. To combat these $I M$ (Intermodulation) sources, reference [7] outlines 
basic causes of intermodulation and presents some techniques which can be undertaken to minimize the problem.

For a linear power amplifier, the relationship between its input and output is

$$
V_{\text {out }}(t)=K V_{\text {in }}(t)
$$

Where $V_{\text {out }}(t)$ is the output signal, $V_{\text {in }}(t)$ is the input signal, and $K$ is the amplifier gain.

For practical amplifiers, the output saturates at some value as the input amplitude is increased. Further, practical amplifiers can have a nonlinear output-to-input characteristic modeled by Taylor's expression such that

$$
\begin{gathered}
V_{\text {out }}(t)=K_{0}+K_{1} V_{\text {in }}(t)+K_{2} V_{\text {in }}{ }^{2}(t)+K_{3} V_{\text {in }}{ }^{3}(t)+\cdots \\
=\sum_{i=0}^{\infty} K_{n} V_{\text {in }}{ }^{n}(t)
\end{gathered}
$$

where $K_{n}=\frac{1}{n !}\left(\frac{d^{n} V_{\text {out }}}{d V_{\text {in }}{ }^{n}}\right)$ evaluated at $V_{\text {in }}=0$.

Here, $K_{0}$ is the output $D C$ (Direct Current) offset term, and $K_{1} V_{i n}(t)$ is the linear term. $K_{2} V_{\text {in }}{ }^{2}(t)$ is the second order term, and $K_{3} V_{\text {in }}{ }^{3}(t)$ is the third order term. The power amplifier will have nonlinear distortion if $K_{2}, K_{3}, \ldots$ are not all zero. A good linear amplifier has $K_{1}$ substantially larger than $K_{2}, K_{3}, \ldots$

We set a two-tone input signal as

$$
V_{\text {in }}(t)=A_{1} \cos \omega_{1} t+A_{2} \cos \omega_{2} t .
$$


For a bandpass system where $\omega_{1}$ and $\omega_{2}$ are within the pass-band and $\omega_{1}$ and $\omega_{2}$ are sufficiently close to one another $\left(\omega_{1} \approx \omega_{2} \gg 0\right)$, the intermodulation products at $2 \omega_{1}-\omega_{2}, 2 \omega_{2}-\omega_{1}, 3 \omega_{1}-2 \omega_{2}, 3 \omega_{2}-2 \omega_{1}$, will fall within the pass-band and will be close to the desired frequency $\omega_{1}$ and $\omega_{2}$. These third- and fifth- order terms will be the main distortion products for band-pass systems such as cellular LTE system. Co-channel interference is created when $\omega_{1}$ and $\omega_{2}$ fall within the pass-band and are spaced at multiples of the channel spacing. Under these conditions, the co-channel interference terms, $2 \omega_{1}-\omega_{2}, 2 \omega_{2}-\omega_{1}, 3 \omega_{1}-2 \omega_{2}$ and $3 \omega_{2}-2 \omega_{1}$, are undesirable interference in the same band for a desired signal. Once generated in the system, this interference cannot be filtered out and will degrade the desired signal. The third- and fifth- order intercept points $\left(\mathrm{IP}_{3}\right.$ and $\left.\mathrm{IP}_{5}\right)$ are used to quantify this interference level.

\subsection{Intercept Points}

Traditionally, the nonlinearity of an RF amplifier is described by $I P_{3}$, which is evaluated by applying two equal test tones $(\mathrm{Al}=\mathrm{A} 2=\mathrm{A}) . I P_{3}$ is the input (or output) power for which the ratio of the linearly amplified tone to its third order intermodulation distortion would be 1 . It is an imaginary point, because saturation comes about before third order intermodulation distortion and is equal to the linear part. $I P_{3}$ is measured for 3 rd order power amplifier nonlinearity. Similarly $I P_{5}$ is defined for the fifth order nonlinearity. $I P_{3}$ and $I P_{5}$ usually suffice to characterize the main nonlinearity in a power amplifier caused by third and fifth order nonlinearities. 
For most power transistors, the $I P_{3}$ parameters normally obtained are listed in the data books. The actual $I P_{3}$ of an amplifier is usually measured using a two-tone test as shown in Figure 2.3. Based on this test, $I P_{3}$ is calculated by

$$
I P_{3}=P_{t}+\frac{I M_{3}}{2}
$$

where $\mathrm{P}_{\mathrm{t}}$ is the power of the original tone signals at the output. This expression is derived directly from the geometric relation shown in Figure 2.3. In order to measure $I P_{3}$ accurately, the tone signal's power $P_{t}$ should be chosen low enough so that the fifth-order intermodulation $I M_{5}$ can be ignored at the output.

Unfortunately, $I P_{5}$ is usually not provided in the data books. However, it can be measured by the two-tone test. $I P_{5}$ can be determined by

$$
I P_{5}=P_{t}+\frac{I M_{5}}{4}
$$

The $I M_{5}$ measurement is shown in Figure 2.4. In this test, the power level of $P_{t}$ is higher than that of the $I M_{3}$ measurement so $I M_{5}$ can be measured reliably.

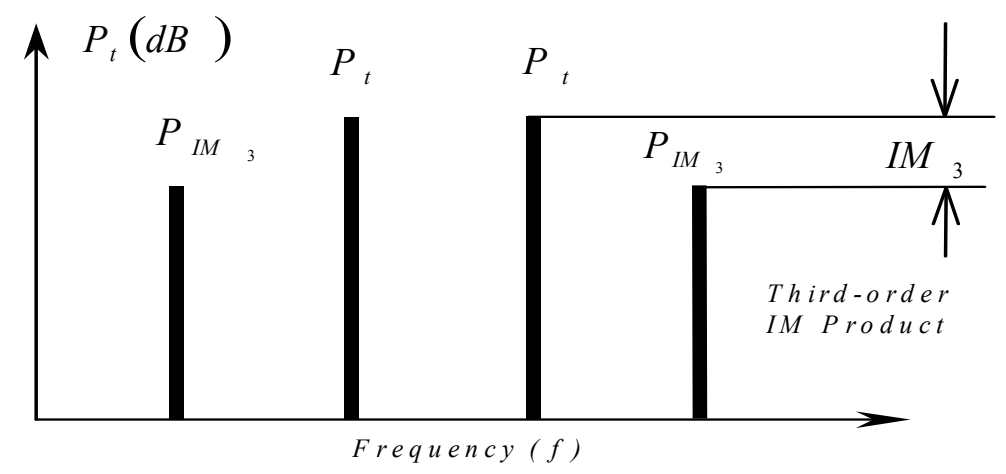

Figure 2.3: Two-tone test for the third-order intermodulation levels. 


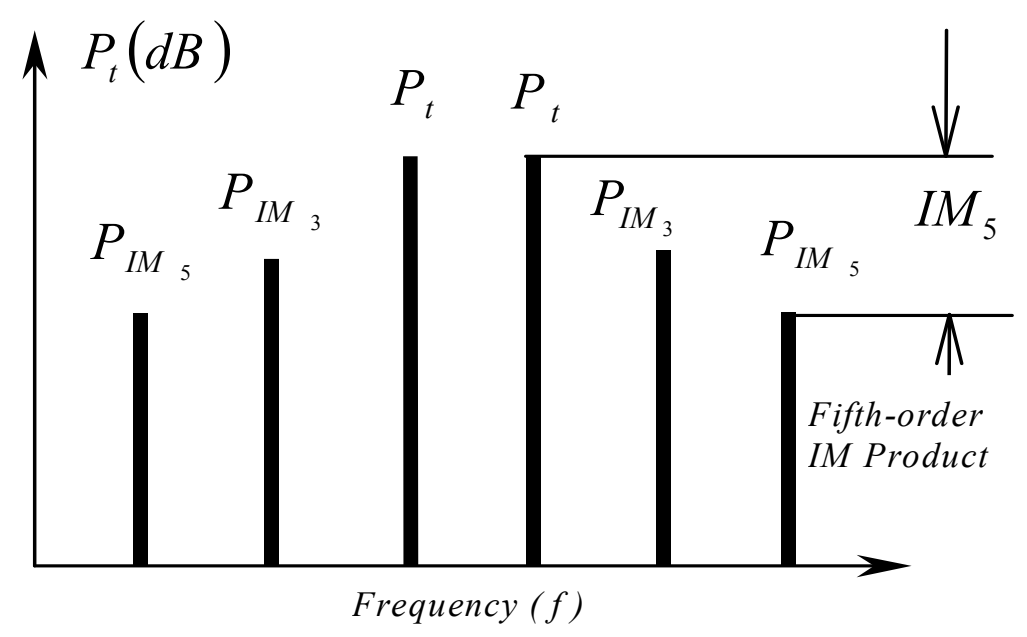

Figure 2.4: Two-tone test for the fifth-order intermodulation levels 


\section{Chapter 3 OFDM Based LTE \& WiMAX Systems}

\subsection{OFDM}

OFDM is a special case of broadband multicarrier modulation method. The main idea of the OFDM technique is to separate the main channel into a lot of orthogonal sub-channels, in which a higher rate single data stream is transmitted over a number of lower rate subcarriers. As an analogy, a FDM channel is like water flow out a faucet, in contrast the OFDM signal is like a shower in which all water comes in one big stream and cannot be sub-divided [8]. In this analogy, the OFDM shower is made up of these many little streams.

\subsection{Advantages of OFDM}

The reason to choose OFDM is that bandwidth can be saved obviously by comparison with the conventional non-overlapping multi-carrier technique. As Fig 3.1 [5] shown, almost $50 \%$ of the bandwidth can be saved by using the overlapping multi-carrier modulation technique, but crosstalk is the main problem to be overcome. The advantage of the OFDM technique, the orthogonality, which is the nature of OFDM, has solved this problem well. 
Ch. 1 Ch. 2 Ch. 3 Ch. 4 Ch. 5 Ch. 6 Ch. 7 Ch. 8 Ch. 9 Ch. 10

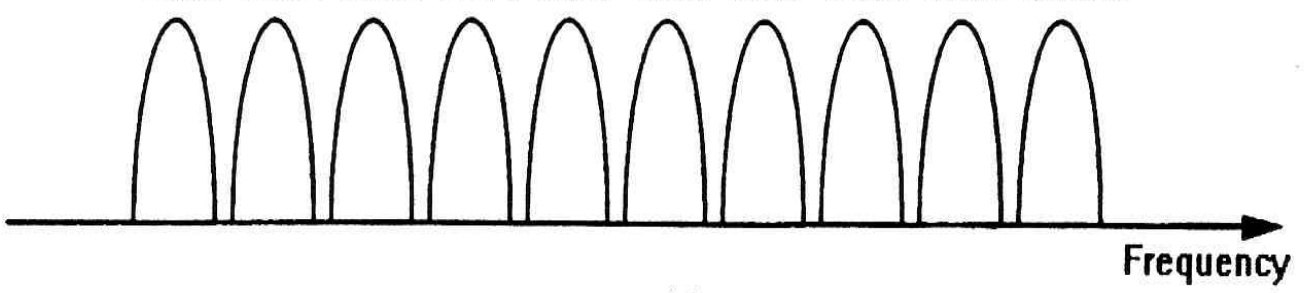

(a)

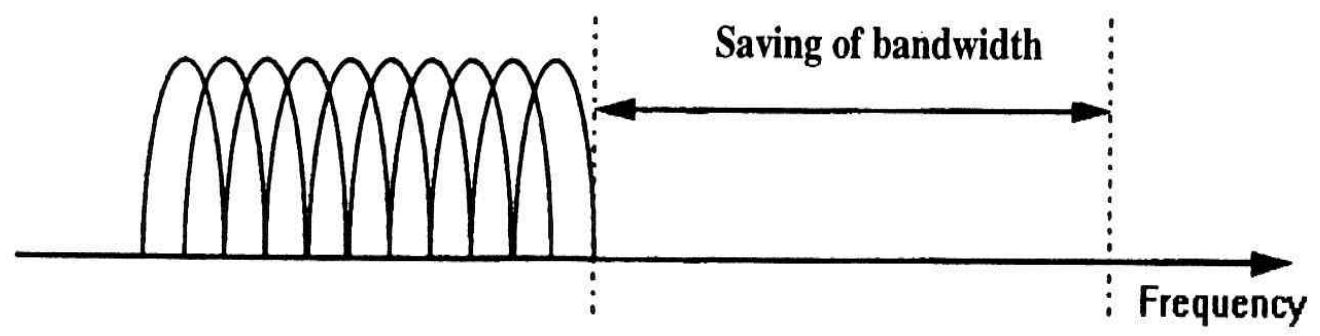

(b)

Fig 3.1(a)Conventional multi-carrier technique;

(b) Orthogonal multi-carrier modulation technique.

Figure 3.2 [9] shows the spectrum of a single modulated OFDM subcarrier. For the spectrum of a multiple OFDM subcarriers, which is shown in Figure 3.3 [9], it is easy to see there is no interference between each subcarrier. 


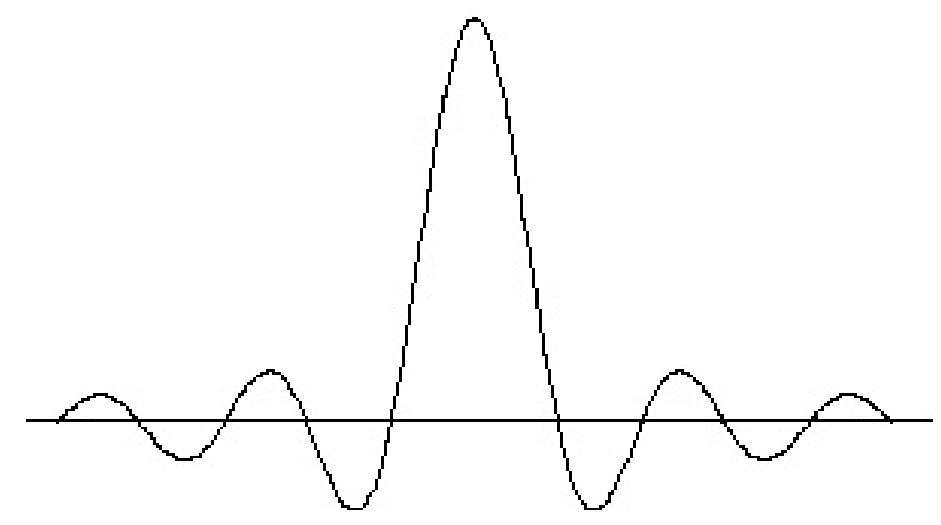

Fig 3.2 Spectrum of a single modulated OFDM subcarrier

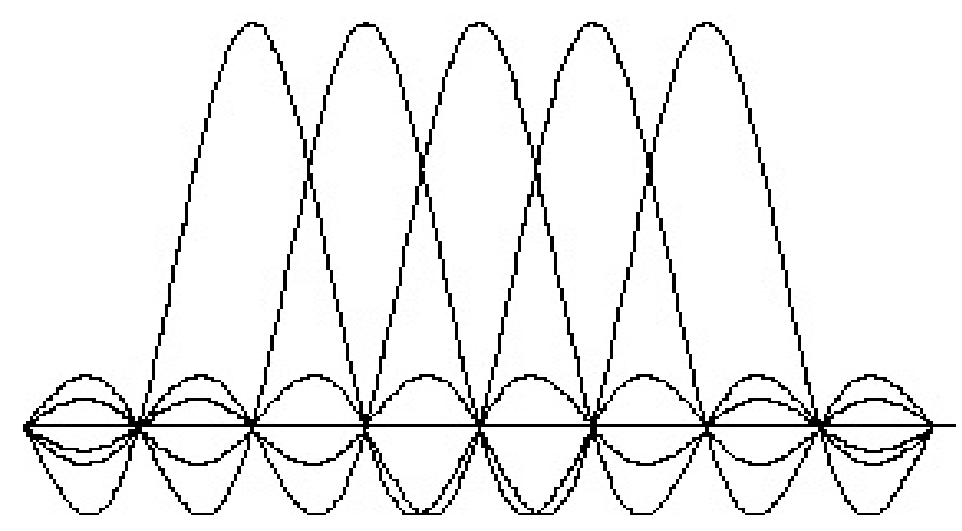

Fig 3.3 Spectrum of multiple OFDM subcarriers of constant amplitude

A crucial feature of OFDM used to reduce the inter-symbol interference (ISI) and inter-channel-interference $(I C I)$ is the cyclic prefix $(C P)$ [10]. The performance of cyclic prefix can be considered as a buffer region where the information from the previous stored symbols is delayed. The receiver has to exclude the samples from the CP which got corrupted by the previous symbol when choosing samples for an OFDM symbol. Further, a sinusoid added with a delayed version of the same sinusoid does not affect the frequency of the sinusoid; only affect the phase and amplitude. As 
a result the receiver can choose $3.2 u$ s samples from the region which is not affected by the previous symbol. As figure 3.4 [5] shown, the available samples can be chosen as the solid and dotted arrow region.

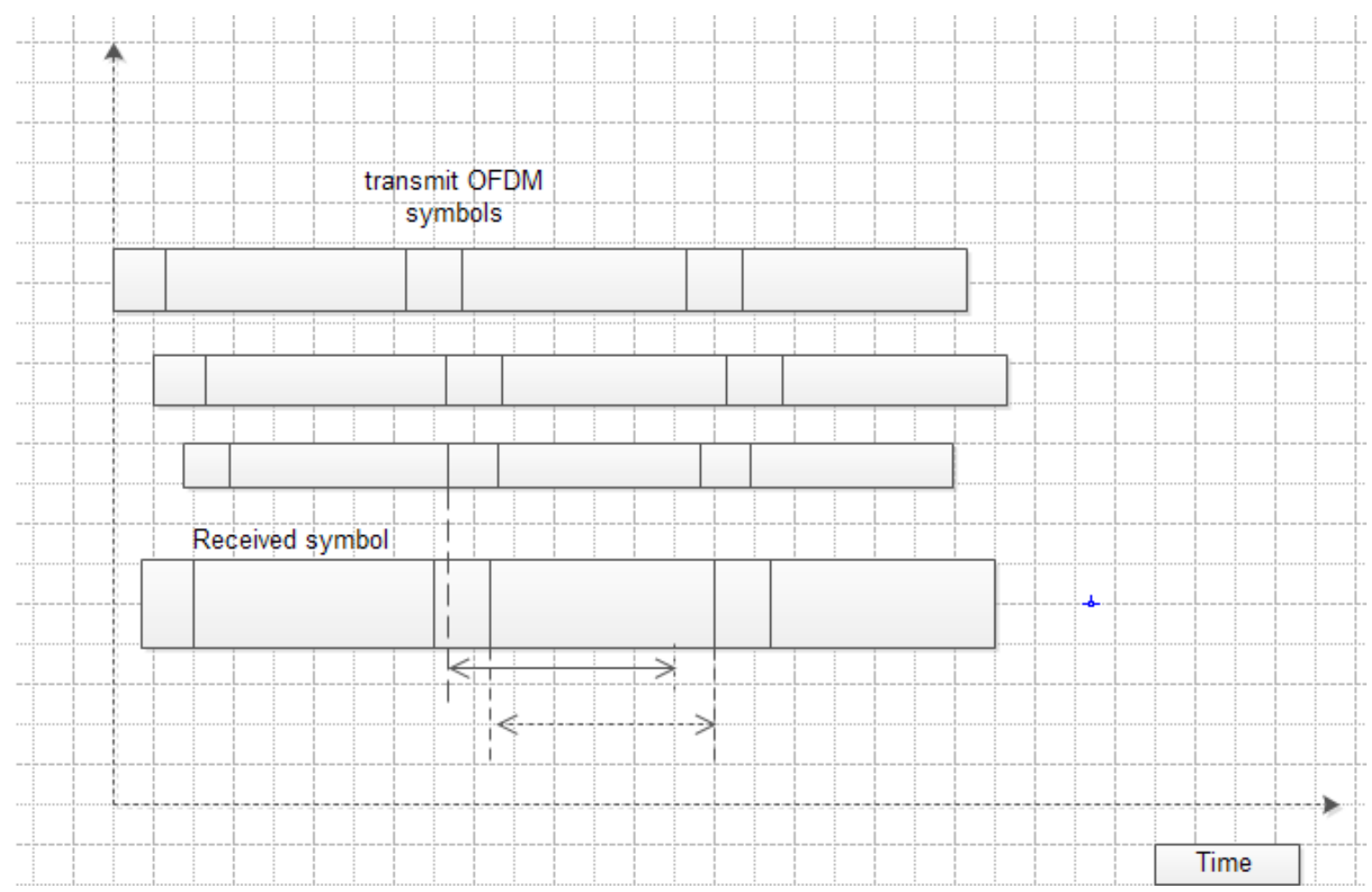

Fig 3.4: OFDM symbol with multipath.

The OFDM technique has been adopted in many standards such as IEEE WIFI 802.11a, IEEE WIMAX 802.16, 3GPP LTE TS 36.211, etc.

\subsection{OFDM Based LTE \& WIMAX Systems}

LTE is a next generation mobile communication system, as a project of the 3rd Generation Partnership Project (3GPP) [11], and WiMAX stands for Worldwide 
Interoperability for Microwave Access [12], and is another emerging wireless technology that provides high speed mobile data and telecommunication services based on IEEE 802.16 standards. Both LTE and WiMAX support frequency division duplexing (FDD) and time-division duplexing (TDD) modes, and have more deployment flexibility than previous 3 Gsystems by using scalable channel bandwidths with different numbers of subcarriers, keeping frequency spacing between subcarriers constant. OFDM with $C P$ is used in the downlink of LTE systems and both the uplink and the downlink of WiMAX systems rather than signal carrier modulation schemes in traditional cellular systems. These two standards have set specific requirements in the terms of the power spectrum density (PSD) of the signal for the control of in-band and out-of-band spectrum regrowth. As a result, it is very important to know the relationship between the spectrum regrowth and intermodulation parameters of the system power amplifier.

The LTE downlink is using OFDM transmission technology. Fig. 3.6 [11] is the block diagram of the transmission of OFDM based LTE system. An LTE symbol is constructed of a guard interval named $\mathrm{CP}$ and the data duration which carries useful data. The $\mathrm{CP}$ denotes as the guard interval. Figure 3.5 [11] shows the three symbols in a slot for the normal CP case. In 3GPP 36.211 LTE standard, the normal cyclic prefix of $144 \times T_{s}(4.69 u s)$ is used to avoid multi-path delay spread. 


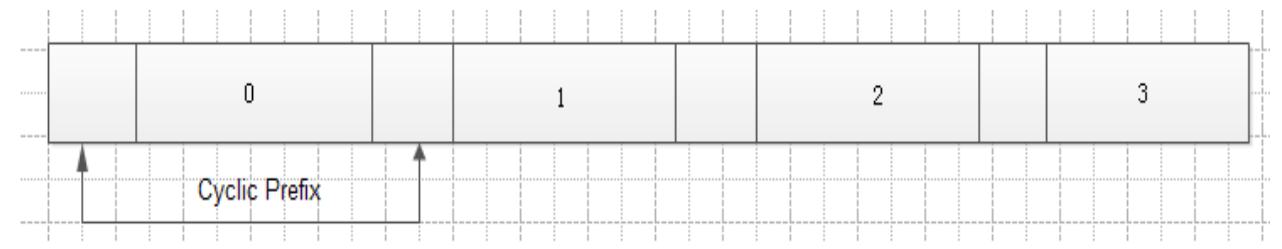

Fig 3.5 OFDM symbol structure for normal cyclic prefix case

The general block diagram of the baseband processing of an OFDM transceiver is shown in Fig. 3.6, which is an example of LTE $10 \mathrm{MHz}$ bandwidth simulation. In this example, the serial high-speed binary input data is separated into many parallel lower speed data bits. As the following the values of binary stream are converted into quadrature amplitude modulatin (QAM) values after interleaving and be prepared to do the inverse fast fourier transform (IFFT) operation. In the next stage a total of 600QAM values is reached per OFDM symbol, which are modulated onto 600 subcarriers by applying the IFFT. A CP is added for making the system robust to multipath propagation. Further, windowing is applied to attain a narrower output spectrum. In Fig. 3.6 the size of FFT is 1024 which the size of used should be the power of two due to FFT implementation advantages. 


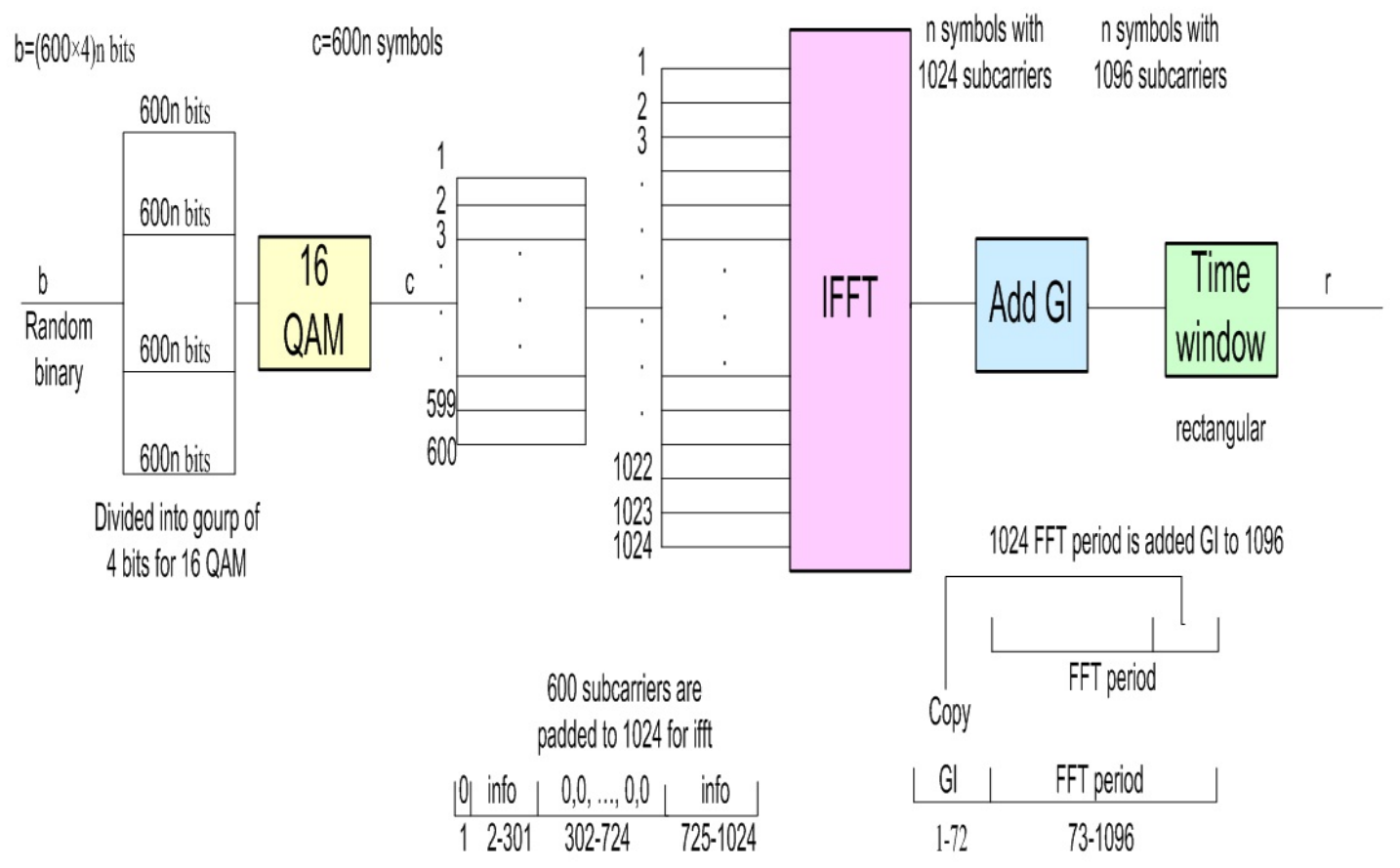

Fig. 3.6 LTE 10MHz bandwidth simulation example.

As the example provided in Fig. 3.6, WiMAX system uses the same OFDM transmission method which is only different in parameters in this topic. Table 3.1 shows the main parameters of OFDM in both LTE and WiMAX system (10MHz). 


\begin{tabular}{|c|c|c|}
\hline OFDM parameters & LTE & WiMAX \\
\hline spacing, $\Delta f$ & $15 \mathrm{KHz}$ & $10.9375 \mathrm{KHz}$ \\
\hline $\begin{array}{c}\text { Number of used } \\
\text { subcarriers, } N_{S C}\end{array}$ & 600 & 865 \\
\hline FFT size & 1024 & 1024 \\
\hline Useful symbol time \\
$T_{\text {Symbol }}$
\end{tabular}

Table 3.1 Parameters used in math model for $10 \mathrm{MHz}$ rate 


\section{Chapter 4 Spectrum Regrowth for OFDM-based LTE \& WiMAX Systems}

\subsection{The Equivalent Mathematical Model of LTE \& WiMAX Signals}

Equivalent mathematical model of LTE and WiMAX can be presented as [5]

$$
b_{n}(t)=W_{T}(t)\left(\sum_{k=-}^{-1} d_{S T / 2} d_{k, n} e^{j 2 \pi k \Delta f\left(t-T_{G I}\right)}+\sum_{k=1}^{N_{S T} / 2} d_{k, n} e^{j 2 \pi k \Delta f\left(t-T_{G I}\right)}\right)
$$

Where $N_{S T}$ is the total number of subcarriers, $\Delta f$ is the subcarrier frequency spacing. Therefore, the resulting waveform of an OFDM data symbol is periodic with a period of $T_{F F T}=1 / \Delta f$, with shifting time $T_{G I}$, which is a guard interval time to create the "cyclic prefix" used in OFDM to avoid the intersymbol interference (ISI) from the previous symbol.

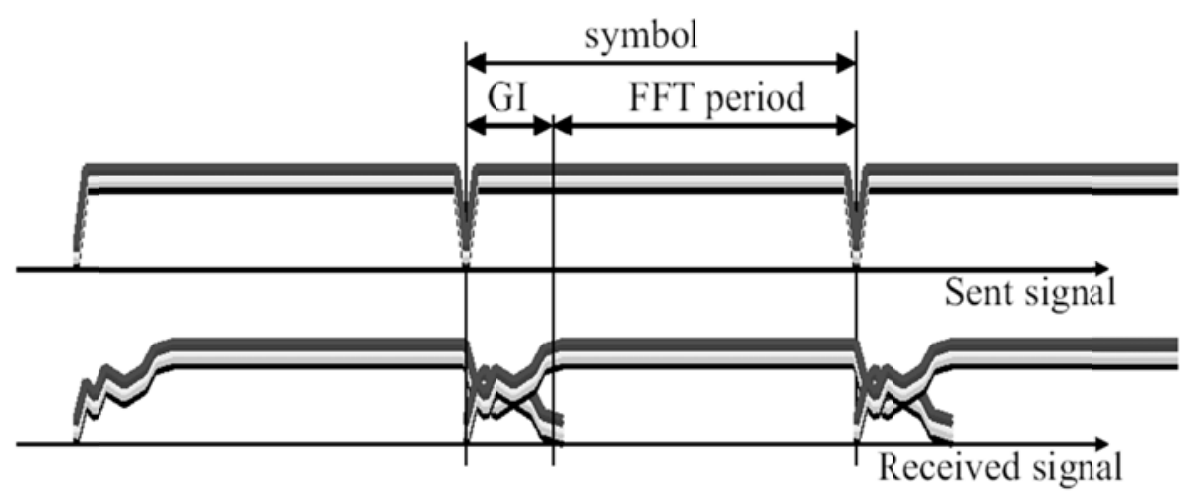

Fig. 4.1 Sent and received signal with a guard interval time

A time windowing function $W_{T}(t)$ is used to set the boundaries of the OFDM symbol. After adding this timing windowing function, the OFDM symbols can be written as: 


$$
\begin{aligned}
& b(t)=\sum_{n=-\infty}^{\infty} b_{n}\left(t-n T_{S}\right) \\
& =\sum_{n=-\infty}^{\infty} W_{T}\left(t-n T_{S}\right)\left(\sum_{k=-N_{S T} / 2}^{-1} d_{k, n} e^{j 2 \pi k \Delta f\left(t-T_{G I}\right)}\right. \\
& \left.+\sum_{k=1}^{N_{S T} / 2} d_{k, n} e^{j 2 \pi k \Delta f\left(t-T_{G I}\right)}\right)
\end{aligned}
$$

where $b(t)$ is the transmitted baseband OFDM signal, and $d_{k, n}$ is the modulated transmitted data in $n t h$ OFDM symbol and the $k t h$ subcarrier. The OFDM subcarrier shall be modulated by using BPSK, QPSK, 16-QAM, or 64-QAM modulation, depending on the transmitted data rate requested. The 16-QAM is chosen to analyze the PSD of LTE and WiMAX signal in this thesis.

In our example, the 16-QAM modulation which is chosen for the LTE and WiMAX system, the encoded data and interleaved binary serial data input should be divided into group of 4 bits and converted into complex numbers representing 16-QAM constellation points. The performance of conversion should be applied to Gray-coded constellation mapping, which is shown in Fig. 4.2. The in-phase (x) value is determined by the input bits $a_{0} a_{1}$, and $a_{2} a_{3}$ determine the quadrature (y) value. The complex output values $d_{k, n}$ are formed by multiplying the resulting $x_{k, n}+j y_{k, n}$ value by a normalization factor $K_{M O D}$, which can be described as

$$
d_{k, n}=\left(x_{k, n}+j y_{k, n}\right) K_{M O D}
$$


and the equivalent form

$$
d_{k, n}=\left(R_{k, n} e^{j \theta_{k, \mathrm{n}}}\right) K_{M O D}
$$

The normalization factor $K_{M O D}$ is chosen as $1 / \sqrt{10}$ for $16-\mathrm{QAM}$ modulation mode. The normalization is used to achieve the uniform average power for all mappings.

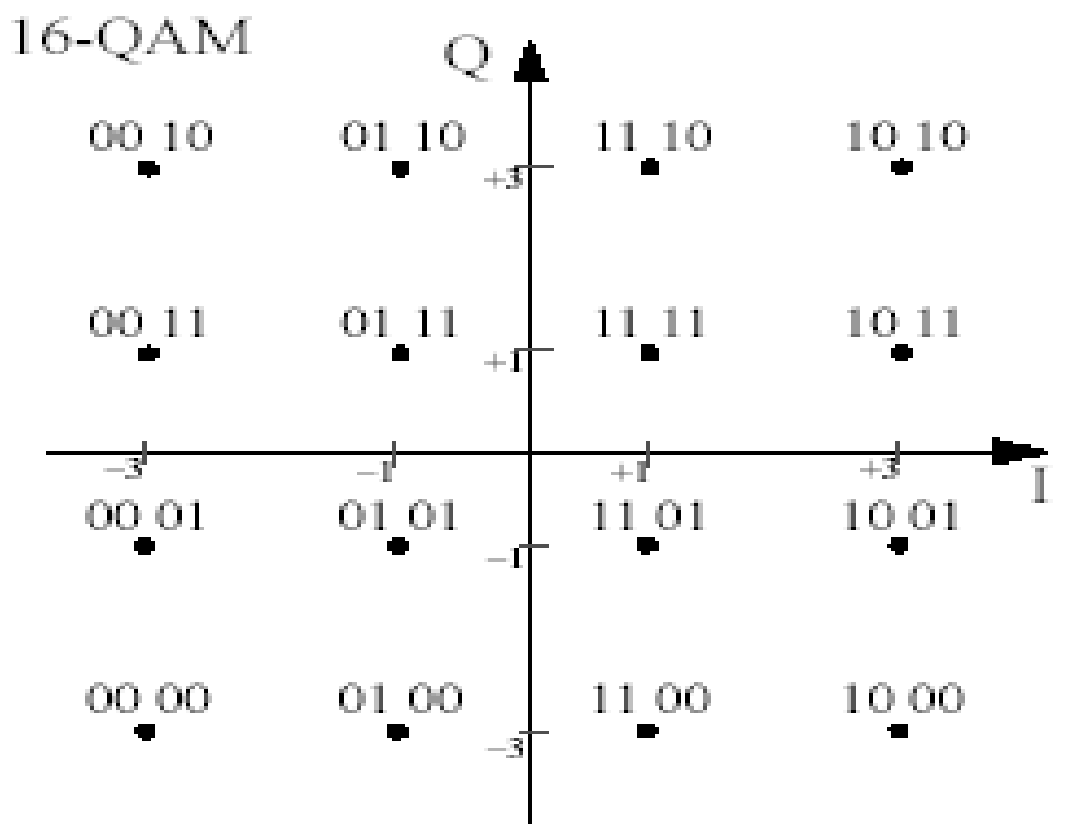

Fig. 4.2 16-QAM constellation bit encoding

After substituting (9) to (7), the transmitted baseband OFDM can be given by

$$
b(t)=\sum_{n=-\infty}^{\infty} W_{T}\left(t-n T_{S}\right)\left(\sum_{k=-N_{S T} / 2}^{-1} d_{k, n} e^{j 2 \pi k \Delta f\left(t-T_{G I}\right)}+\sum_{k=1}^{N_{S T} / 2} d_{k, n} e^{j 2 \pi k \Delta f\left(t-T_{G I}\right)}\right)
$$




$$
=\sum_{n=-\infty}^{\infty}\left(\sum_{k=-N_{S T / 2}}^{-1} e^{j 2 \pi k \Delta f\left(t-T_{G I}\right)}+\sum_{k=1}^{N_{S T} / 2} e^{j 2 \pi k \Delta f\left(t-T_{G I}\right)}\right) R_{k, \mathrm{n}} K_{M O D}
$$

Further, the actual transmitted signal $s(t)$ can be expressed by its baseband envelope in

$$
\begin{gathered}
s(t)=\sum_{n=-\infty}^{\infty} \sum_{k=-N_{S T} / 2}^{N_{S T} / 2} R_{k, n} K_{M O D} W_{T}\left(t-n T_{S}\right) \\
\times \cos \left[2 \pi k \Delta f\left(t-n T_{S}-T_{G I}\right)+\theta_{k, n}\right] \cos \left(2 \pi f_{c} t\right)-
\end{gathered}
$$

$$
\sum_{n=-\infty}^{\infty} \sum_{k=-\frac{N_{S T}}{2}}^{\frac{N_{S T}}{2}} R_{k, n} K_{M O D} W_{T}\left(t-n T_{S}\right) \times
$$

$$
\begin{aligned}
\sin \left[2 \pi k \Delta f \left(t-n T_{S}-\right.\right. & \left.\left.T_{G I}\right)+\theta_{k, n}\right] \sin \left(2 \pi f_{c} t\right) \\
& =\sum_{n=-\infty}^{\infty} \sum_{k=-N_{S T} / 2}^{N_{S T} / 2} R_{k, n} K_{M O D} W_{T}\left(t-n T_{S}\right) \\
& \times \cos \left[2 \pi k \Delta f\left(t-n T_{S}-T_{G I}\right)+\theta_{k, n}+2 \pi f_{c} t\right]
\end{aligned}
$$


$=$

$$
\begin{aligned}
& \operatorname{Re}\left\{\left[\sum_{n=-\infty}^{\infty} \sum_{k=-N_{S T} / 2}^{N_{S T} / 2} R_{k, n} K_{M O D} W_{T}\left(t-n T_{S}\right) \times\right.\right. \\
& \left.\left.e^{j\left[2 \pi k \Delta f\left(t-n T_{S}-T_{G I}\right)+\theta_{k, n}\right]}\right] e^{j 2 \pi f_{c} t}\right\}=\operatorname{Re}\left\{r(t) e^{2 \pi f_{c} t}\right\}(
\end{aligned}
$$

Where $\operatorname{Re}\{$.$\} denotes the real part of \{$.$\} , and$ $r(t)=\sum_{n=-\infty}^{\infty} \sum_{k=-}^{N_{S T} / 2} N_{S T / 2} R_{k, n} K_{M O D} W_{T}\left(t-n T_{S}\right) \times e^{j\left[2 \pi k \Delta f\left(t-n T_{S}-T_{G I}\right)+\theta_{k, n}\right]}$ is the baseband envelope of the actual transmitted signal $s(t)$, and $f_{c}$ denotes the carrier frequency. The $r(t)$ can be written as following:

$$
\begin{gathered}
r(t)=\sum_{n=-\infty}^{\infty} W_{T}\left(t-n T_{S}\right)\left(\sum_{k=-N_{S T} / 2}^{-1} e^{j 2 \pi k \Delta f\left(t-T_{G I}\right)}\right. \\
\left.+\sum_{k=1}^{N_{S T} / 2} e^{j 2 \pi k \Delta f\left(t-T_{G I}\right)}\right) R_{k, n} K_{M O D} \\
=\sum_{k=-N_{S T} / 2} g_{k}(t) e^{j 2 \pi k \Delta f t}+\sum_{k=1}^{N_{S T}} g_{k}(t) e^{j 2 \pi k \Delta f t}
\end{gathered}
$$

where

$\mathrm{g}_{\mathrm{k}}(\mathrm{t})=\sum_{n=-\infty}^{\infty} W_{T}\left(\operatorname{tn} T_{S}\right)\left(\sum_{k=-N_{S T} / 2}^{-1} e^{j 2 \pi k \Delta f\left(t-T_{G I}\right)} \sum_{k=1}^{N_{S T} / 2} e^{j 2 \pi k \Delta f\left(t-T_{G I}\right)}\right) R_{k, \mathrm{n}} K_{M O D}$

is the mathematical representation of an OFDM subcarrier signal. 
An OFDM symbol is constructed as an IFFT of a set of $a_{k, l}$ which is the modulated transmitted data in the lth OFDM symbol and the kth subcarrier. A time window $W_{T_{\text {Symbol }}}$ is applied to the individual OFDM symbols in order to make the spectrum decrease more rapidly. $N_{S C}$ is the total number of used subcarriers. $\Delta \mathrm{f}$ is the subcarrier frequency spacing. $T_{C P}$ is a guard interval time to create the 'cyclic prefix' to avoid the intersymbol interference(ISI) from the previous symbol, and $T_{S}$ is sample period.

The general expression for the PSD of an OFDM baseband signal can be obtained as:

$$
\begin{aligned}
& P_{r}(f)=R_{S}\left\{\sum_{K=-\frac{N_{S C}}{2}}\left|W_{T_{\text {Symbol }}}(f-k \Delta f)\right|^{2}\right. \\
& +\sum_{K=1}^{\frac{N_{S C}}{2}} \mid W_{T_{\text {Symbol }}}(f \\
& \left.-k \Delta f)\left.\right|^{2}\right\}
\end{aligned}
$$

Table 3.1 shows the different main parameters in LTE and WiMAX system.

Fig. 4.3 [13] shows this predicted spectrum in comparison with the simulated spectrum in MATLAB and the spectrum measured on a vector signal generator of both the LTE and the WiMAX signals. 

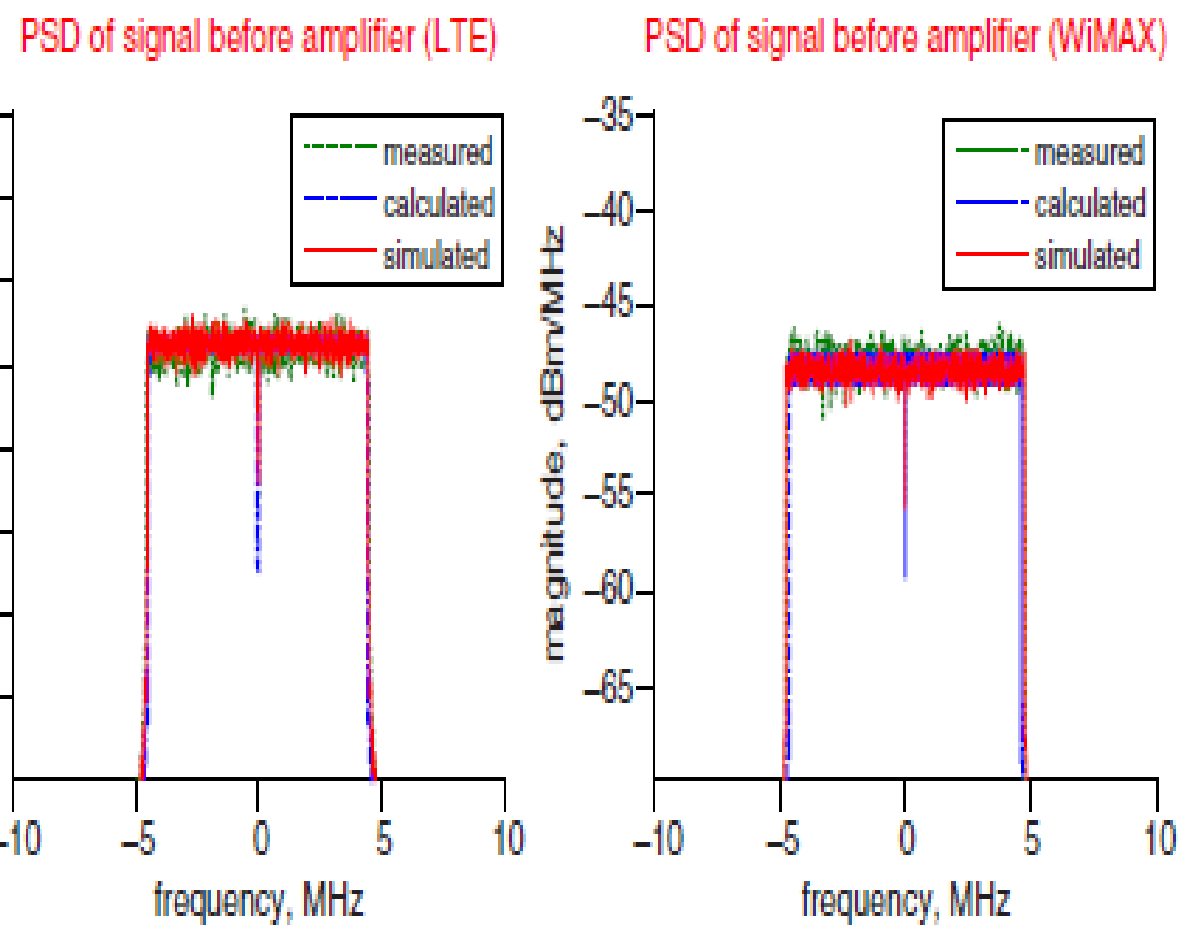

Fig. 4.3 Power spectrum comparison of downlink LTE and WiMAX signal

\subsection{Amplified Signals for LTE and WiMAX}

In general the ideal amplifier is a linear device in its linear region. In practice the output of the amplifier will not be exactly scaled to the input due to the non-linearity, which means the amplifier works beyond the linear region. The output of an amplifier can be written as

$$
y(t)=O\{s(t)\}=F[r(t)] \cos \left\{2 \pi f_{c} t+\varphi[r(t)]\right\}
$$

where $O\{$.$\} denotes the operation of an amplifier, F\{$.$\} is AM/AM conversion, and$ $\varphi\{$.$\} is AM/PM conversion. The phase distortion can be ignored using Taylor series$ model since the only interesting thing is in the output band near the carrier frequency $f_{c}$. Therefore (14) can be presented as 


$$
y(t)=O\{s(t)\}=F[r(t)] \cos \left(2 \pi f_{c} t\right)
$$

We can derive the Taylor model of a high power amplifier by letting $\tilde{y}(t)=F[r(t)]$,

$$
y(t)=\sum_{i=0}^{\infty} a_{2 i+1} s^{2 i+1}(t)
$$

We only considered the odd-order terms in the Taylor series model, since the spectra generated by the even-order terms are at least $f_{c}$ away from the center of the passband which can be negligible. Therefore (17) is used for the high power amplifier

$$
y(t)=a_{1} s(t)+a_{3} s^{3}(t)
$$

Here, the coefficient $a_{1}$ is related to the linear gain $G$ of the amplifier, and the coefficient $a_{3}$ is directly related to $I P_{3}$, which can usually be obtained from the manufacturer's data sheets of the RF power amplifiers. For an amplifier with gain compression $\left(a_{3}<0\right)$,

$$
a_{1}=10^{\frac{G}{20}}, \quad a_{3}=-\frac{2}{3} 10^{\left(\frac{-I P_{3}}{10}+3 \frac{G}{20}\right)}
$$

$y(t)$ can be written as following equation by substituting the input passband signal $s(t)=r(t) \cos \left(2 \pi f_{c} t\right)$ into $(17)$

$$
y(t)=\tilde{y}(t) \cos \left(2 \pi f_{c} t\right)
$$

and

$$
\tilde{y}(t)=\tilde{a}_{1} r(t)+\tilde{a}_{27} r^{3}(t)
$$


here

$$
\tilde{a}_{1}=a_{1}, \quad \tilde{a}_{3}=\frac{3}{4} a_{3}
$$

\subsection{PSD of Amplified Signals}

The PSD of $y(t)$ can be determined by the PSD of $\tilde{y}(t)$

$$
P_{y}(f)=\frac{1}{4}\left[P_{\tilde{y}}\left(f-f_{c}\right)+P_{\tilde{y}}\left(-f-f_{c}\right)\right]
$$

Further the PSD of $\widetilde{y}(t)$ can be derived by the Winer-Khintchine Theorem

$$
P_{\tilde{y}}(f)=F\left\{\varphi_{\tilde{y}}(\tau)\right\}
$$

where $F\{$.$\} is the Fourier Transform of \{$.$\} and \varphi_{\tilde{y}}(\tau)$ is the autocorrelation of $\widetilde{y}(\mathrm{t})$.

Also $\varphi_{\tilde{y}}$ can be expressed by definition as following

$$
\varphi_{\tilde{y}}=E\{\tilde{y}(t) \tilde{y}(t+\tau)\}
$$

where $E\{$.$\} is the mathematical expectation of \{$.$\} . According to the expression above,$ $P_{\tilde{y}}(f)$ can be presented as

$$
\begin{aligned}
& P_{\tilde{y}}(f)=F\{E\{\tilde{y}(t) \tilde{y}(t+\tau)\}\} \\
& =F\left\{E\left\{\tilde{a}_{1} r(t)+\tilde{a}_{3} r^{3}(t)\right\}\right\} \\
& \quad \times\left[\tilde{a}_{1} r(t+\tau)+\tilde{a}_{3} r^{3}(t+\tau)\right]
\end{aligned}
$$


Finally the power spectrum $P_{y}(f)$ can be presented in terms of the amplifier nonlinear parameter $I P_{3}$, and the linear output power $P_{0}$ of the amplifier as

$$
\begin{gathered}
P_{y}(f)=\left(2 P_{0}-12 P_{0}{ }^{2} 10^{\frac{-I P 3}{10}}+18 P_{0}{ }^{3} 10^{\frac{-I P 3}{5}}\right) \frac{P_{1}\left(f-f_{C}\right)}{N_{S C}} \\
+\left(48 P_{3}{ }^{3} 10^{\frac{-I P 3}{5}}\right) \frac{P_{3}\left(f-f_{C}\right)}{N_{S C}{ }^{3}}
\end{gathered}
$$

As the result we can have $P_{3}=P_{1} \otimes P_{1} \otimes P_{1}$, and $\otimes$ is convolution operator. $P_{0}=$ $a_{1}^{2} N_{S C} / 4$ is the linear output power of the amplifier. Further, if a frequency band is defined by $f_{1}$ and $f_{2}$ outside the passband, the required $I P_{3}$, for a given out-of-band emission level $P_{\operatorname{IM3}}\left(f_{1}, f_{2}\right)$ specified in LTE or WiMAX standard can be calculated.

\subsection{Results}

The calculated result is compared with simulation by Matlab and the measurement made on a real RF power amplifier. The LTE and WiMAX signals are generated by an Agilent E4438C ESG vector signal generator. $1.9 \mathrm{GHz}$ is chosen as the carrier frequency. Some measurements of out-of-band emission levels of LTE and WiMAX have been taken using a CRBAMP-100-6000 power amplifier, which is designed by Crystek. This amplifier has a $20 \mathrm{dBm} I P_{3}$ with a $20 \mathrm{~dB}$ gain. $1 \mathrm{KHz}$ is chosen as the resolution bandwidth. As Fig. 4.4 [13] shown, the derived amplified spectrum $P y(f)$ compared to the Matlab simulated spectrum and the one measured on an 89600 vector signal analyzer for the downlink LTE signal and the WiMAX signal. The simulated and measured RF amplifier spectra agree with the analytically predicted spectrum in both the passband and the shoulder area. 

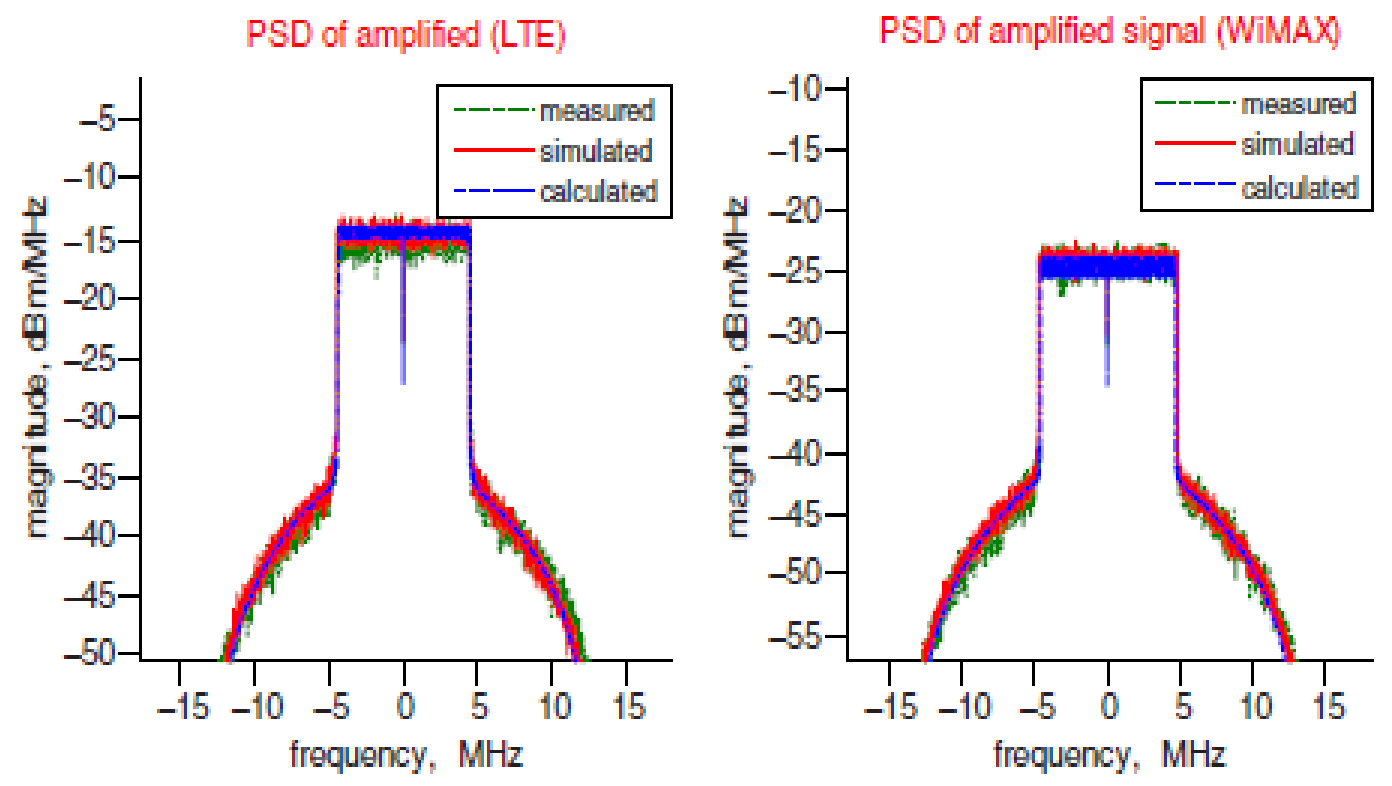

Fig. 4.4 Power spectrum comparison of amplified downlink LTE and WiMAX signal 


\section{Chapter 5 Concluding Remarks}

\subsection{Summary}

The research results in this dissertation provide OFDM-based wireless

communication system designers the method to specify and measure spectrum regrowth using simple RF power amplifier intermodulation descriptions. Spectrum administrators can manage and plan spectrum allocation efficiently by using the results of this research.

\subsection{Main contributions}

The research results in this dissertation have the following contributions:

1. The PSD expressions of the signals before amplification are derived for OFDM-based LTE and OFDM-based WiMAX system, which cannot be considered as a simple rectangule is shown by the research results in this dissertation.

2. The PSD expressions of the out-of-band emission levels for signals after amplification caused by the nonlinearity of the amplifier are derived for OFDM-based LTE and WiMAX systems in terms of the RF power amplifier's intermodulation coefficients $I P_{3}$, as well as the power level and bandwidth of the signal.

3. A powerful design tool has been derived in expressions of $I P_{3}$ as a function of spectrum regrowth requirements. This will help power amplifier designers choose components. 
4. The calculated result is compared with simulation by Matlab and verified by the measurement made on a real RF power amplifier. The RF instruments for measurement are Agilent E4438C ESG vector signal generator and E4438C ESG vector signal analyzer.

\subsection{Future Research Topics}

Based on the analysis method we used in OFDM-based LTE and WiMAX systems, we will research on other wireless communication standards using OFDM technology, such as ultra wide bandwidth (UWB) systems. The challenge of UWB analysis is its wide bandwidth $(528 \mathrm{MHz})$, which may require more complete math modeling for RF power amplifiers and spectrum analyzers supporting higher bandwidth for experimental verification.

Digital pre-distortion, the nonlinearity correction of ADC, DAC, and Mixer, are the other research topics we will focus on, and the result of this thesis is the fundamental theory to derive the inverse function of power amplifier nonlinearity in order to linearize RF power amplifiers. 


\section{References}

[1]. Q. Wu, H. Xiao, and F. Li, Linear RF power amplifier design for CDMA signals: A spectrum analysis approach, Microwave Journal, vol.41, pp.22-40, Dec. 1998.

[2]. H. Xiao, Spectrum modeling for linear RF power amplifier design for digital cellular communication signals, Ph.D. dissertation, Portland State University, May 1999.

[3]. C.M. Liu, H. Xiao, Q. Wu, and F. Li, Spectrum modeling of an RF power amplifier for TDMA signals, Microwave Journal, vol.44, pp.88-109, Apr 2001.

[4]. C.M. Liu, H. Xiao, Q. Wu, and F. Li, Spectrum design of RF power amplifier for wireless communication systems, IEEE Transactions on Consumer Electronics, vol.48, pp.72-80, Feb. 2002.

[5]. C.M. Liu, Spectral Modeling and Nonlinear Distortion Analysis of OFDM Based Wireless LAN Signals, Ph.D. dissertation, Portland State University, June. 2005.

[6]. X. Li, H. Xiao, C.M. Liu, and F. Li, Nonlinearity Analysis of RF Power Amplified TD-SCDMA Signal, ISCP 2010.

[7]. Sevic, John F., Staudinger, Joseph, Simulation of adjacent-channel power for digital wireless communication systems, Microwave Journal, pp 66-80,Oct 1996

[8]. C. Langton, Orthogonal Frequency Division Multiplexing (OFDM) Tutorial, copy right 1998, 2002, www.complextoreal.com. 
[9]. M. Rumney, LTE and the Evolution to $4 G$ Wireless Design and Mesurement Challenges, copy right 2009, Agilent Technologies Publication.

[10]. K. Sankar, Cylcic prefix in Orthogonal Frequency Division Multiplexing, Feb $17,2008$.

[11]. 3GPP, 'TS 36.211-10.2.0, E-UTRA Physical channels and modulation',July 2011.

[12]. IEEE 'Standard 802.16 Part 16: Air Interface for Broadband Wireless Access Systems', May2009.

[13]. X. Li, B.S. Chen, C.M. Liu, X.R. Wang, K.R. Cho, and F. Li, Spectrum Modeling and Regrowth for $4 G$ Wireless Signals, Electronics Letters on Institution of Engineering and Technology, vol 48, pp 244-245, Feb 16, 2012. 